\title{
1
}

\section{Sensing Absence: How to See What Isn't There in the Study of Science and Security}

\author{
Brian Rappert
}

What is not of concern in social and political life is the ever-shifting shadow to what is of concern. ${ }^{1}$ At any one time only certain topics will garner the limelight in public discussions. Yet, what remains off the agenda can be judged to be equally, if not more, important than what is so. This is perhaps most obviously evident in the manner priorities change over time and across locations. Swine flu, human trafficking, animal experimentation, HIV/AIDS, and Ebola outbreaks are just some instances of topics that have waxed and waned as matters of apprehension.

Much the same can be said about how any topics come to be understood. While issues or events could be described in almost any number of ways, only certain framings are likely to be prevalent at a given time and place. Yet which ones are widespread can be highly consequential in suggesting what is at stake. As, for instance, James Revill and Brett Edwards note in their chapter in this volume, disfiguring acid attacks frequently perpetuated around the world are rarely described as chemical weapon attacks within the parlance of international diplomacy. Through the connections made and not, ways of seeing can obscure or sideline considerations. In this sense, presence and absence come bundled together in what is concealed within what is revealed.

With any newfound heightened awareness, regard can be cast on the reasons for past indifference or apathy. For instance, some have argued that ethical, legal, and social analysis of science has often been reactive to scandals, catastrophes, experiments, and so on (rather than proactive in setting out a positive future agenda), and has tended to focus on new technologies (rather than the major public health problems measured in terms of burden of disease). ${ }^{2}$ Likewise, avoiding "strategic surprise" by learning from the past has long led to soul-searching about 
disciplinary preoccupations in areas concerned with national security (see Walker's chapter on technological surprise).

With any level of attention, regard can be given to the consequences of that attention. Individuals, organizations, professions, and publics can be blind to an issue because of the lack of concern, can be blinded to aspects of an issue because of how attention gets selectively focused, ${ }^{3}$ or can be blinded by an issue because it detracts regard from other matters.

Within the study of social and political life then, regard for what is being attended to needs to be combined with what is not: what issues are not considered, what is not said, what matters are rendered hidden, what grievances never get formed, what paths are never pursued. That might be because some questions never get asked, pertinent information is never shared, forums for collective discussion do not exist, some individuals actively work against others knowing, and so on. All such social processes characterized by absence are-at least in principalopen to empirical and theoretical investigation.

Absence in Science, Security and Policy poses a basic question: How can those examining the ethical, legal, and social implications of science become more mindful about the implications they are not addressing? A starting point for this proposal is the contention that key challenges for the examination of modern science, technology, and medicine include: (i) how issues are identified as matters of concern; and (ii) how they become formulated as problems in need of redress. The basic move proposed in this volume is a shift, in a sense, backward. The aim is one of attending to the whys and hows associated with what is not: for who, when, and under what circumstances are matters not treated as significant. A number of sub-questions that address themes of ethical blindness, taken-for-granted assumptions, and the social construction of reasoning will be central, including:

- How have some ethical, legal, and social implications of science become rendered (and not) issues of concern?

- What are the everyday routines, practices, social structures that shape whether and how topics become (dis-)regarded?

- How have scientists and others fostered attention to or distanced themselves from the questionable applications of their work?

While the central aim of Absence in Science, Security and Policy is simple in its formulation, addressing it is not. A starting assumption of this volume is that questioning taken for granted activities is indispensable 
in approaching absent concerns. At stake in forwarding our analysis of this topic of "non-concerns" are complex considerations of how facts, figures, concepts, and arguments should be made sense of and by whom. As will be contended, this requires asking critical questions about the preoccupations guiding social research too. Rather than being reactive and probing the overt and obvious, inquiry should aim to cultivate thinking afresh. To do so requires more than asking whether this or that topic has been given sufficient regard. Rather, it requires inquiring into the conditions that structure what is or is not missing. In other words, "how" and not just "what" must be examined, but in a way that questions the contingencies and commitments of "how."

The composition of the chapters in this collection exemplifies this imperative to question the priorities of social research while we utilize it to make sense of the world. One long-standing divide in social studies of the life sciences has been between those who are concerned about ELSA (ethical, legal, and social aspects) or ELSI (ethical, legal, and social implications) and those concerned about its security dimensions. ${ }^{4}$ Overall, the latter largely has been the purview of those working within international relations, peace studies, and security studies, whereas the former have become mainstays within sociology, politics, anthropology, and ethics. The result has been a weak cross fertilization of ideas. In contrast, Absence in Science, Security and Policy seeks to bring together security and nonsecurity-related analyses in order to ask how they can learn from each other.

This introductory chapter challenges us to think afresh about these matters through the following structure: the next section opens up what it means to suggest that there is concern or not through unpacking the basic descriptors of absence and presence. As will be contended, these two notions are often treated as opposites; however, this distinction is difficult to sustain. Instead it is necessary to ask how presence and absence are interrelated. When this is done, as a dichotomous designator, "non-" is likely to be crudely blunt if not downright unhelpful. Answering the question "What is absent?" requires attending to questions such as "Absent for whom?," "When?," "In what manner?," and "By which practices?." Contrasts between in-group and out-group, front stage and backstage, public and private, as well as official and non-official, are just some of the possible starting lines for cleavage. The third section also asks to what extent the social and ethical analysis of science is absent regard for what is missing from it.

On the basis of a nuanced sense of absence and presence, the fourth section then considers what it can mean to talk about "concern" and 
"non-concerns" as well as the necessary cautions associated with inquiring about them. This discussion, in turn, provides the basis in the fifth section for asking what kind of empirical and conceptual sensitivities might be needed for this volume.

The tension that runs throughout this chapter is how to handle, on the one hand, the desire to question the meaning of notions such as "absence," "presence," and "(non)-concern" while, on the other hand, necessarily trading on a sense of their meaning. Rather than somehow seeking to resolve this tension, the intention is to develop sensitivities for appreciating what is at stake in order to open up possibilities for thought. As part of fostering such sensitivities, this chapter (as with the other in Part I) reflects on what new metaphors might guide our investigation. I advance the metaphor of the autostereogram in the final section as one way of fostering re-appreciations-to create a space through attending to absences.

Through its varied preoccupations, this chapter touches on wideranging aspects and literatures. For that reason it will likely demand much of the reader. This situation very much exemplifies the topics under investigation. The more one opens up to absences the more they abound, but the appreciation of their prominence does not leave us lesser, but rather richer.

\section{The interweavings of presence and absence}

In asking how those groups or individuals attentive to ethical, legal, and social implications of science can become more mindful about what they are not addressing, the arguments in this volume are infused with the descriptors of "absent" and "present." This section offers an appreciation of the relation between the two. This then provides the basis for a nuanced understanding of what it means to describe a topic as (not) "of concern" in the next section.

To start, it can be noted that "absence" and "presence" are often understood in terms of degrees. If the question is posed: "Is X present?," then the answer need not be only "yes" or "no." Even if we take that question as pertaining to physical perception, the response can be "more or less." Over time all sorts of things-mountains, civilizations, ideas-gradually come and go. Perhaps controversially, the existence of an individual life itself can be approached as a matter of degreewith near conception and end-of-life conditions confounding neat binary classifications. ${ }^{5}$ The assertion that everything exists in degreesincluding "whole" numbers such as $1,2,3 \ldots$-was a foundational 
tenet for the fuzzy mathematics that underpins the operation of many of our modern adaptive electronic devices. ${ }^{6}$

In part because of degrees, the relation between the descriptors of "absent" and "present" is complex. What is on show often defies any simple characterization. The physical world provides numerous examples of this. Vacuums may be devoid of substance, but they can be pulsating with energy. The chairs on which people write and read books generally seem solid enough. At an atomic scale though, they are characterized by material emptiness-“99.9999999999999 per cent empty space" to be roughly exact. ${ }^{7}$ At a subatomic scale, the protons and neutrons that make up the atomic nucleus are themselves characterized by material emptiness.

Attention to degree can be used to prompt attention to aspect. It might well be argued that what counts is not how much "material" is taken up by electrons, protons, and neutrons, but rather the sense of substance for us generated by the natural forces at work. The application of the term "absence" and "presence" then turns on what feature of something is deemed relevant. As a result, both terms might be used for description, but for different reasons and in multiple ways. Memorial is the activity of trying to keep present in thought that which is not proximate for perception. Take another example more closely related to the themes of this volume. For those with dementia, Schillmeier has argued that objects in the world can be both present and absent. They are present to hand as observable things out in the world. And yet, they are only-and merelypresent. With no remembered past relations to those with dementia, objects have no future. With no past or future, objects "lead into nothing and to nowhere." 8 They are absent of meaning. In these ways, "demented objects" can be said to be both present and absent at the same time.

Complexity also derives from the manner in which determinations of absence and presence can be relative. That is to say, they are made on the basis of comparison. To contend a topic is missing from the 10 o'clock news, for instance, involves making a judgment about how much it should be covered in the first place. Determinations about whether there is silence-that is an absence of noise-depend on expectations of what sound there should be. This is not likely to be a matter of universal accord and would almost certainly vary by setting. It is the potential for conflicting judgments about whether a given something is "there enough" that enables individuals to ask what sort of regard should be given in the first place.

Absence can imply presence because to be empty is to be empty of something; something that was there, should be there, or in the future 
might again come back. For instance, perhaps starting with Yves Klein's 1958 exhibition The Void, a number of contemporary artists have produced galleries and museums emptied out of traditional works of art. The displaying of "empty space" - white walls and bare rooms-where there is the anticipation for objects of a certain type has been recurring modern motif for provoking debate. The ability of such emptied spaces to disturb, bewilder, and anger draws on a sense of what else should be present from what else is so. ${ }^{9}$ Similarly, attempts to sequester awaysuch as in erasing secret government sites from maps or removing the deceased from places of dying-can create an absence that evokes a sense of what is missing. ${ }^{10}$

An example of how presence can imply absence is given in the interpretations prominent scholars have made of photographs. Rather than the photo fixing an immobile moment, it has been interpreted as a trace ever haunted by what is outside the frame. As Sontag wrote, "To take a photograph is to participate in another person's (or thing's) morality, vulnerability, mutability. Precisely by slicing out this moment and freezing it, all photographs testify to time's relentless melt."11 What is there, in other words, points away from itself to that which is no longer so. The philosopher Noë discussed the pictorial presence of the photos as making the people present precisely as otherwise absent. ${ }^{12}$ Informed by psychoanalysis, Leader has contended art in general evokes a sense of what is beyond representation..$^{13}$ Still more widely, for some such as Franke, presence as absence is ubiquitous aspect of language when it is maintained that "All that is said, at least indirectly and implicitly, testifying to something else that is not said and perhaps cannot be said." ${ }^{14}$ Derrida has perhaps been the most influential intellectual in advancing the notion that the meaning of words should be seen as in the negative; that is to say, terms take their specific meaning from the possible range of meanings they are not. His work has served as the inspiration for many attempts to understand how absence implies presence and presence absence. ${ }^{15}$

The two terms are also relational when the meaning and significance of what is absent depends on what is present and vice versa. ${ }^{16}$ In terms of the former, when only a few lines of text are blacked out in documents released as part of a Freedom of Information request, the resulting "holes" on the page can become pregnant with significance. ${ }^{17}$ Depending on the surrounding notes, in music the lack of sound at any specific moment might be either deemed a "silence" that should be recognized as meaningful (or even "itself" heard ${ }^{18}$ ) or just a passing lull that gives way to the next note. As well, depending on the surrounding words and situation, in an interview the lack of spoken words at any 
specific moment might be either deemed a noteworthy gap or momentary happenstance. ${ }^{19}$ These examples suggest how absence figures in our lived experiences. ${ }^{20}$

In terms of how presences take their meaning from absences, consider two examples. When military intelligence is communicated in the public domain-as in the now infamous February 5, 2003 presentation by US Secretary of State Colin Powell to UN Security Council on "Iraqi WMD"-then what is shown can take on an inflated status for those that assume it must only be the tip of the intelligence iceberg. Some maintained that this would be so because authorities would prudently hold some evidence back from the public gaze. ${ }^{21}$ Likewise, in relation to commercial confidentiality, the explicit withholding of some data from view or the presentation of overtly manipulated data can work to suggest much unstated expertise lies beyond the partial information made visible. ${ }^{22}$ Meyer's call to develop a "relational ontology of absence" draws attention to the need to attend to the two-way relationality between absence and presence in material culture. ${ }^{23}$ Graves, museums, memorabilia are some of the forms of materiality that signal immateriality.

Relationality can entail dependency. A room in a building is as much defined by what is there in some obvious material sense (supporting beams, plaster boards, bricks) as what is not (the empty space enclosed). The latter gives a room the room which can be occupied. Without that potential, it is not a room. Within the unfolding, moment-to-moment interactions of conversations, the importance of silence and talk can be reliant on one another. The meaning of these both is shaped by situational expectations and they help constitute those interactions as particular kinds of situations (ordinary conversation, professional talk, office banter). ${ }^{24}$ The classic Chinese text Tao Te Ching is a multifacet engagement with that which remains beyond the bounds of expression. It also includes consideration of how what not is present is constitutive of what is so. A direct reference to the dependency of what is there on what is not is given in the passage:

Thirty spokes meet at a nave;

Because of the hole we may use the wheel.

Clay is molded into a vessel;

Because of the hollow we may use the cup.

Walls are built around a hearth;

Because of the doors we may use the house.

Thus tools come from what exists,

But use from what does not. ${ }^{25}$ 
Many different sorts of objects-bells, flames, art museums, murder mysteries-require some bounding of and dependency between absences and presences to give them function. ${ }^{26}$ But note the absences, gaps, and spaces in-between are not simply a state of nothing or some blank void. It is the air in the bell that enables sound to ring out. In a nontrivial way, a bell is not a bell without the "emptiness" its form envelops.

Absence and presence can exist in relations of causality. Presences that lead to absences are commonplace. Too much of the hormone dihydrotestosterone on the scalp can result in the absence of hair. To talk of absence that cause presence is commonplace too. The absence of rain can be said to be the cause of a bush fire. The lack of exposure to the sun can result in Vitamin D deficiency which, in turn, causes bone deformities and so on. While often taken for granted in everyday talk, the standing of such "negative causality" can be a matter of dispute. To say that a famine is caused by the absence of international aid, for instance, might upset some sensitivities. Like so many of the issues about how to blend absence and presence in this chapter, the appropriateness of the characterization depends on the purposes at hand.

Efforts to make present are also invariably bound up with the production of absence: Disclosures about the world always have an end, and so any description necessarily creates a sense of that which remains outside of it. For some topics-such as the historical analysis of daily cultural life-what can be appreciated through the remaining documentary evidence signals the vast terrain of what remains unappreciable because it has been lost in time. ${ }^{27}$ In this respect, seeing is a way of not seeing because of what gets left out of the picture formed. As well, what is stated provides the very terms that can be further elaborated. More words provide more commentary, but they also mark a terrain that could be scrutinized for what remains outside of what is given.

\section{Inquiry and absence}

Despite noting these varied interweavings of what is there and what is not, Absence in Science, Security and Policy ever hazards collapsing into a superficial employment of the designation "absent." This stems from the basic demand associated with the underlying justification for this volume: attending to what is missing and absent.

Elsewhere, others have argued too that there has been insufficient regard for what is absent compared to what is present. ${ }^{28}$ In a special volume of Social Epistemology on absence, Frickel contended that the 
field of Science and Technology Studies (STS) is dominated by "knowledge making, not the non-production of knowledge; our accounts typically privilege action over inaction; we study processes of becoming, or emergence, far more than processes of winnowing or submergence; we are more interested in beginnings and successes than endings and failures." ${ }^{29}$ Similar apprehensions have been expressed about how fields such as bioethics are typically directed toward the dissection of manifested binds and dilemmas. ${ }^{30}$

While such observations can be valid for the purposes they were offered, what is demanded at other times though is the need for considerable caution in treating the label of absent as simply indicating some void or lack. Instead of asking whether something is there, it is necessary to ask how absence implicates presence and vice versa. In this regard, for instance, despite the justifications for the evaluations made in the previous paragraph, it is possible to advance a less stark reading of STS and bioethics: that through their persistent flagging of the contingency of knowledge production and ethical decision-making, both (if only implicitly and indirectly) continually point to what remains in the shadows. For instance, understanding how certain forms of expertise become dominant and institutionalized simultaneously speaks to what gets marginalized and how. ${ }^{31}$ Likewise in International Relations, regard for the contingent process of how security problems are identified-as in securitization theory-speaks to what is not. ${ }^{32}$

Going a step further though, it is possible to note that notions of absence and presence within academic literature exist in a dynamic relation with one another. For instance, in the desire to give a voice to experiences marginalized by mainstream culture, many of those who studied "race" and ethnicity in the past in the West did so by casting attention toward "the Other." What was insufficiently acknowledged could then be acknowledged-what was hitherto absent could be made present. As has become more widely accepted though, this move itself produced an unquestioned domain: that of the presumed (white) Self. In more recent decades, anti-racist scholarship has expressly turned to the cultural production of concepts of "whiteness." In attending to how these often unacknowledged but pervasive collective identifications are formed, these studies seek to question the conventions of both social life and social science. ${ }^{33}$ Similarly, Brekhus offered a generalized approach for querying the implications of what is off the agenda in his call for the study of the mundane. ${ }^{34}$ As he contended, all too often social researchers are attracted to the "extraordinary." This not only results in areas being un-investigated, it leads to "marked" topics being 
treated as more distinct, exaggerated, and yet also more uniform than would be otherwise.

Taking the previous paragraphs together suggests two points: (i) easy generalizations of absence in academic disciplines can belie what has been made present; (ii) attempts to make present can lead to the production of absences.

These dynamics play out in contemporary discussions about ignorance. In recent years, across various disciplines renewed calls have been made for its examination. As part of this, what is deemed "unknown" should not be conceived as blank space that results from some inability to know. Instead, ignorance can be deliberately manufactured, actively sought, or it can serve as a prompt for learning. ${ }^{35}$ 'Leading advocates of the turn to ignorance, such as Proctor, have contended that ignorance has fared as the poor cousin to knowledge. He advanced the notion of "agnotology" to complement the longstanding field of epistemology. ${ }^{36}$

Yet, despite the ways in which ignorance has been positioned as previously absent in academic study, it is possible to offer other interpretations. One way this could be done is through employing a more nuanced sense of what has been made present. We might, for instance, note the ways in which previous research has again and again provided analysis that speaks to ignorance; albeit perhaps not necessarily under that particular label. ${ }^{37}$ Croissant, for instance, surveyed a wide range of scholarship undertaken across a number of decades that investigated the creation of "agnosis"; including the sociology of risk, political studies of ideology, postcolonical studies, and critical race studies. ${ }^{38}$ Whether such studies are treated as informing an understanding of ignorance proper is highly consequential. This informs determinations about both the extent of current "knowledge gaps" as well as what is required to address them.

Another way to resist a simple characterization of the absence of the study of ignorance is to ask how evaluations made to this effect are the results of ongoing academic specialization. For instance, at least some discussions about ignorance within anthropology appear to neither be informed by or to inform related discussions in other disciplines. ${ }^{39}$ To the extent that the formation of academic specialisms means that researchers know more and more about less and less, then it needs to be appreciated that the disciplinary structure of academia itself acts as an engine for fostering ignorance. ${ }^{40}$

The mapping provided in this section whereby what is absent melds and mixes with what is present indicates the type of receptiveness 
needed in asking what issues associated with science are "not of concern" and how. While "absent" and "present" are adjectives and "presence" and "absence" nouns, understanding how these designations matter for the study of social life entails the study of verbs. The goal then is not to posit a new kind of object (i.e., absent ones) that is attributed as doing things in the world; akin to physicists identifying dark matter as central to the composition of the universe. ${ }^{41}$ Absence and presence are taken to signal dynamic processes between knower and known that can have considerable implications: some individuals will be cast as experts, others skilful enough to be able to discern what is missing, and others not able to see what is in front of them. As a result, the active processes under examination should be understood as consequential for how both the subjects and objects of concern become conceived.

What the chapters of Absence in Science, Security and Policy seek to avoid then is treating presence and absence as distinct states, wherein the contributors then assume the role of knowledge holefillers. Rather, notions of absence and presence are dynamically intertwined. Elsewhere, I forwarded the metaphor of a "whirlwind" to characterize how absence and presence interact with the writings of social research. ${ }^{42}$ Vortexes such as whirlwinds take their shape from the interactive movement between what is there and what is not-meaning what is absent cannot be defined without reference to what is present. In addition, it is the interaction of the two that accounts for the emergent forces set in motion by vortices. What the "whirlwind" metaphor does not acknowledge though is the relation of absence and presence to the observer. New metaphors are vital in order to refrain from crude but commonplace orientations-a point revisited below.

Attentive to the dynamisms of the melding and mixing, the contributors in this volume treat the manifestation of societal concern about science as secured, mediated, diminished, threatened, and sustained through potentially complex movements of what might be called "presencing" and "absencing." A goal of the remainder of this Introduction is to trace out how concern can be made into a topic of study, while also attending to what remains outside this or any analysis.

\section{The interweavings of concern and nonconcern}

While the previous section opened up the understanding of "absence," this one turns to a related term in the title for this book: concern. 
Building on the previous argument, it asks what it means to speak about the absence of apprehension as well as how such situations could figure a topic for study.

As with absence, it is possible to advance a complex, somewhat Janus, picture of the treatment of (non-) concerns with the social sciences and other domains of study. While disciplines such as sociology and international relations are generally drawn toward matters that animate debate and interest, what does not so has also figured as an implicit topic of commentary. ${ }^{43}$ The "social problems" and "social movements" literatures are ones where this is perhaps most clearly evident. In seeking to understand how certain topics become deemed "problems" that mobilize action, these fields constantly gesture toward what does not get deemed a problem and what does not mobilize action.

For those analysts wishing to examine what doesn't become a concern and for whom, one way the existing literature could be reinterpreted to inform to the issues of this volume is by reversing the lines of sight presented. Analysis of the establishment of the priorities in an international disarmament NGO (it campaigns on a, b, c) could be taken as indicating what isn't of concern ( $x, y, z)$. The reason why topic $\mathrm{x}$ isn't recognized then is the lack of the factors that lead to the prioritization of a, b, c. Further, the lack of recognition of $x$ need not even be regarded as problematic. Time and resource constraints might make such marginalization essential. Treated in the manner outlined above, absent concerns would be derived as leftovers. Herein, appreciating what is not requires little more of social analysis than learning to subtract.

Yet it seems highly plausible to argue that the task of examining concerns is more demanding than this. ${ }^{44}$ A particular matter might be hard to grasp, deliberately concealed, too mundane to be appreciated, purposely not made public, unintelligible, too foregrounded to be noticed, collectively disowned, lost in history, beyond expression, or barred from comprehension. ${ }^{45}$ Each of these calls for subtlety in investigation. As well, in de-anchoring analysis from something overt to something not so, in the study of what is not of concern the range of possibly relevant considerations multiplies dramatically. And since those considerations relate to what is not taking place, evidencing their counterfactual relevance is not straightforward. Stated differently, what needs attention is not simply this or that missing recognition. Instead it may be necessary to attend to discourses, "worldviews," paradigms, assumptions, forms of power, modes of (un)knowing, and so on, that precondition what is possible for individuals or groups. ${ }^{46}$ 
Past strategies employed in explicit efforts to identify "non-concerns" have included comparing topics with shared pertinent similarities in order to account for variations in how they are recognized, evaluated, and acted upon; forwarding normative principles to query conventions; probing struggles for appropriate language; using extreme cases of activity to identify inactivity; undertaking historical study to signal counterfactuals and counter-scenarios; utilizing quantitative research methods and noncooperative game theory to indicate possibilities beyond those that are most often manifest; and engaging in structural analysis to identify unacknowledged matters. ${ }^{47}$

With respect to science as specific topic, many studies speaking to the nullifying of concerns have investigated the practices of professional boundary work. For instance, Cunningham-Burley and Kerr examined how the accounts of geneticists enabled them to secure the cognitive authority necessary to secure public research funding, while placing themselves as authority figures about the social implications of genetics, while also distancing themselves from the responsibility for negative dimensions. ${ }^{48}$ Firth and colleagues examined boundary work within infertility clinics that meant ethical concerns were not identified with its day-to-day practices. ${ }^{49}$

\section{Inquiry and concern}

As suggested in the previous argument then, it is not only the "nonconcerns" of those under study that need attention, but of those doing the study-social analysts, researchers, scholars, practitioners, and so on. As such, some have argued that empirical investigation undertaken with an eye on what is judged to be absent as a concern helps produce more robust analysis. It does so by fostering alternative hypotheses, setting out strategic agendas, avoiding reactivity, and encouraging regard to negative evidence. ${ }^{50}$ For instance, the academic literature into "social problems" and "social movements" is extensive. Yet, without systematic consideration directed toward what does not become a concern, this literature hazards are becoming conservative. ${ }^{51}$ The scope for apprehension with the limitations of the empirical is substantial; it extends far beyond the personal commitments of individual investigators. ${ }^{52}$ Social research is undertaken in circumstances that lead to the lack of recognition of some matters that, in turn, helps reproduce conditions of selective regard. Formal constraints on what can be studied, the structures of research organizations, the peculiarities of funding agencies, and professional expectations about what is worth knowing are just some of the 
factors that delimit attention. ${ }^{53}$ Raising further apprehension, Rayner argues that some social research has had the effect of diverting and distracting societal and professional regard; resulting in certain matters not being acknowledged and some possibilities never being considered. ${ }^{54}$

Any descriptions of social "implications," "troubles," and so on necessarily provide selective and partial simplifications. ${ }^{55}$ In this they frame what is going on and why, as well as prefigure what needs doing and by whom through what description is included and what they do not include. The framing of issues is as pervasive and inevitable as it is disputable and contingent. The contingency and commitments of any descriptions especially come to the fore when it is looked at in terms of what it does not include. As such, engaging with the demands and dilemmas of seeking to bring absent concerns front and center can be one way of engaging with the general conditions of analysis front and center. ${ }^{56}$

More than this though, descriptions are consequential. The very procedures and routines designed to address ethical concerns can effectively render them unrecognized. To study patient care dilemmas in hospitals as matters of "ethics" can reinforce relations of hierarchy that result in the worries of some not being aired. ${ }^{57}$

Another possible benefit is that novel questions can be posed. This is so when attending to what is absent leads to critical reflection on the preoccupations and predilections of social actors and researchers. For instance, that might mean asking questions such as the following:

How do procedures meant to identify issues stymie regarding them as a concern?

In what ways can empirical research distract, divert, and delay recognition and action?

How is "what counts as data" the effects of and how does it affect existing social practices, networks, and routines?

What research has gone undone? On whose behalf is it meant to be done?

Why are things not otherwise?

In the ways outlined above, empirical social research can be part of the reasons why some matters are rendered unrecognized, not a concern, not worth acting upon, and so on. In the effort to study what is absent then, the status quo, and what foils efforts to move on from it demand consideration. To do this almost certainly requires looking beyond a single policy or decision. What it ultimately requires by way of investigation though is an open matter. 
Many of the issues raised in this section played out in classical arguments between pluralist and post-pluralist theories about the exercise of power centered on whether it was possible to study what did not happen-what did not get on the agenda ${ }^{58}$ or what demands were never formulated in the first place. As a project of making present what was absent, post-pluralists sought to move beyond visible political contests. In this way, it was possible to propose otherwise hidden relations of domination and subordination. This identification provided a basis for questioning what was not happening in political life as well as what was not happening in the study of political life. ${ }^{59}$

Making a case for what is sidelined through power though raised thorny issues about how analysts are positioned. For instance, Stephen Lukes's classic book Power: A Radical View ${ }^{60}$ set out a strategy for assessing why certain wants, preferences, and grievances never formed in the first place. The job of the social analyst herein was that of an expert who sought to identify what was latent. Because it was latent, simply relying on interviews or surveys with members of the public would not be sufficient. Instead, analysts had to marshal an argument for being able to recognize about others what they might well not recognize about themselves. That meant at times relying on individuals' reports about their grievances, but also at times pointing to individual's actual or real interests. In this way, marking the absence of concern then was irrevocably tied to the making of authority. Thinking more widely, arguments about what has been disclosed through academic analysis, who is (really) capable of comprehending it, and to what extent it is distinct from everyday thought are all part and parcel of how many academics claim expertise. ${ }^{61}$ Since the time of Power: A Radical View's initial publication in the mid-1970s, the project of explaining what is not happening has been more tentative and complicated because of doubts about whether "real interests" exist, and even if they do, whether social scientists can determine them. ${ }^{62}$

The identification of the "real" that can serve as a foothold for analysis is a feature of many studies orientated toward the "not." Dimitrov, for instance, asked why only some international environmental concerns led to the creation of corresponding interstate policy agreements. ${ }^{63} \mathrm{His}$ explanation centered on the extent of substantive information about the consequences of environmental concerns; in particular, information about their transnational boundary effects. Accounting for action and inaction in this way though relied on judgments made about the factual status of the problems with forest and coral reef degradation. 
Within the "social problems" tradition, anxiety has long been expressed about how social researchers can end up clandestinely importing in assumptions about the nature of the problems they are addressing. When the goal of this tradition was widely taken as the realist identification of neglected concerns that merited greater appreciation, then a sense of the facts of the matter was central to the enterprise. Some claims about the world might be critiqued, but others need to be taken for granted to advance some sense of the problem. More generally within social research, questions can always be asked about what has been left out of attempts to understand why certain matters have not merited regard. ${ }^{64}$

Within the constructivist turn in recent decades in social problems, the orientation has been to treat the meaning attributed to problems as the contingent result of the activities of individuals and groups. The emphasis is with "claims making" rather than "making claims." And yet, as Woolgar and Pawluch contended, notionally constructivist forms of analysis utilize selective questioning in the manner in which they often take it as their role to explain the indefinite relation between shifting accounts of a problem and some underlying (real) situation. ${ }^{65}$ Any understanding of the latter though is necessarily as crafted by analysts as other accounts. As such, un-interrogated and un-acknowledged footholds end up propping up constructivist arguments about the actual state of underlying situations.

More recently, Latour has questioned the ever unpacking of facts as it is typically conceived in social theorizing. As he argues, usually the goal of theorizing is one of unearthing, exposing, revealing, and so on, the social basis for notionally objectified factual claims. In short, incessant deconstruction is the mission-at least, that is of deconstruction of other people's facts. The ones cherished by analysts are often excluded from this kind of scrutiny. In its place he proposes a kind of realist orientation to "matters of concern." ${ }^{66}$ The shift could be characterized as a movement from soulless deconstructivism to positive constructivisma shift from critique as typically conceived since Immanuel Kant to the attempts to understand the materially heterogeneous assemblages that enable the liveliness of things to emerge, be maintained, and move individuals. Responding to Latour, Lynch has argued that instead of starting with "matters of concern" as a framing category, it would be more advantageous to see how, by whom, for whom, and so on, concerns about science and technology are made relevant and contested. ${ }^{67}$ It is the latter approach of asking what counts and how so as a concern that is aligned with many of the chapters of this volume. 


\section{Possible approaches}

The previous argument would suggest that knowing what is not of concern can be tricky. In the manner that partiality is a constitutive part of seeing, it is unwise to approach the study of what is absent through simply trying to peer more intently or to strive to get below the surface of appearance. It would also seem questionable to just change our direction of view or redouble our efforts to gather facts. Arguably, the demands of identifying what is not of concern by some metric should not be regarded as containable through a particular technique or method. Since the method entails the mobilization of bias, it invariably creates a sense of the missing. Also, the desire to regard what was hitherto not regarded comes with its own tempting allures that need to be avoided. For instance, the belief that this can be done in some authoritative fashion can lead to clinging to some ways of understanding as definite.

The complicit and self-referential dynamics at work suggest the necessity for heightened sensitivities rather than set solutions. Those include the need to (i) disrupt taken-for-granted ways of understanding; (ii) become curious about how to marshal claims about empirical facts; (iii) inquire how we relate to our objects of study; and (iv) ask how opportunities for knowing are enabled and constricted because of the qualities of the object of study and our methods for studying them. Such sensitivities require becoming attentive to tensions: How can there be any easy sense of knowing what is not being avoided while also commenting on what is lacking? How can concentration on specific topics be combined with a sensitivity about what is outside of them? When can the demand to attend to what is not being attended to cease?

In the spirit that underlies this Introduction, in posing these questions it is important to recognize that much valuable thought has already been dedicated around these types of sensitivities. One way of dealing with the demands above is to seek modest, situated truth claims that attend to the question "For what?" "Nons" can be identified for a specific purpose rather than for all seasons. That is to say, it is possible to rethink the purpose of study. Taken in a Deweyan pragmatic sense, rather than trying to decisively determine what is absent, for who, and how, effort can be directed toward establishing experimental forms of inquiry that can foster questioning, learning, and dialogue. ${ }^{68}$ In other words, research needs to be approached as a process- $\mathrm{a}$ form of intervention-one, for Dewey, that took problematic situations as its object of attention. This emphasis on the question of understanding "For what?" contrasts with the typical goal of achieving some generalized understanding of the world-a goal expressed in such diverse pursuits 
as the explanation of power as well as actor network theory inspired delineations of "matters of concerns." 69

Another approach to thinking about the types of sensitivities helpful for the themes of this book is given in Maria Puig de la Bellacasa's reorientation of Latour's "matters of concern" into "matters of care."70 The latter locates itself within a tradition of regard to affective states of attachment, commitment, and practice. Such a reframing places at the forefront what has been neglected-such as devalued forms of labor or activities defined as superfluous. This is done in order to engender practices of care that can, in turn, lead to novel forms of understanding. ${ }^{71}$ That is to say, Puig de la Bellacasa makes the case for rethinking the motivations for study when she argues:

[i]n strongly stratified technoscientific worlds, erased concerns do not just become visible by following the articulate and assembled concerns composing a thing, nor does generating care happen by counting the participants present in an issue. In the perspective proposed here, generating care means counting in participants and issues who have not managed or are not likely to succeed in articulating their concerns, or whose modes of articulation indicate a politics that is "imperceptible" within prevalent ways of understanding.... ${ }^{72}$

Herein, it is necessary to ask about the effects of theorizations. This task of asking what effort makes something neglected has been pursued elsewhere too. For instance, Bacchi provides a sustained analysis of how problems affecting women are identified and how they are evaluated with particular emphasis on the consequences of what is not problematized and what possibilities for actions do not arise. ${ }^{73}$

Alternative sensitivities can be promoted through unorthodox ways of asking "What's there?" That is to say, it is possible to rethink the objects of study. Law and Lien outline two contrasting ways of making sense of this question with broadly constructivist approaches to science and technology:

On the one hand [some suggest] that since different groups have different locations and social and material interests, it is unsurprising that they also have different perspectives. This social constructivist way of thinking is grounded, at least implicitly, on the assumption that the cosmos is endowed with a single order (for instance a single social structure, or a single material world). ${ }^{74}$ 
and then on the other hand there can be a focus:

on practices rather than people or groups, [...] avoid[ing] assuming that there is a grounding order. Instead they say that practices generate orders. Ordering becomes a relational and performative effect of practices, and since the latter vary, this also means that ordering varies too. As a result, questions of ontology (the kinds of objects or entities that exist) are detached from general assumptions about the character of the cosmos and become a matter for empirical investigation. At the same time, the cosmos turns from a general framing order into contingent sets of orders, ordering processes, disorders, and unknowable fluidities. ${ }^{75}$

In the latter treatment favored by Law and Lien, it is not simply that some same object is conceived of in different ways by different groups in society, but rather that it is necessary to ask how different objects come to be through different practices. ${ }^{76}$ Such contrasting ontological presumptions lend themselves to different ways of thinking about how matters are rendered missing, how to characterize the concerns associated with them, and what research design is appropriate. ${ }^{77}$

\section{Sensitivities}

In trying to heighten sensitivities for attending to what is absent, the remainder of this chapter turns attention elsewhere. I want to examine some of the base assumptions often made about how social research sizes up the objects of its study. In doing so, the goal is to rethink the relations of our studies and through doing so nurture new possibilities.

A joke might help bring some issues into relief:

A woman comes across someone kneeling on the pavement under street lamp.

"Are you alright?," she asks.

"I've dropped my house keys," he explains.

After several minutes of searching together, she asks "Where exactly do you think you dropped them?"

"Somewhere over there I think," he says pointing down the street.

Perplexed, she asks "Then why are we looking here?"

"Because this is where the light is." 
The "Streetlight Effect" joke trades on the readily understandable desire to find something missing. The final line revealing the search is being conducted around the ease of hunting due to the location of the light, rather than the likelihood of finding due to the location of keys, renders the search farcical.

The Streetlight Effect though is often recounted for more than generating laughter. Instead it can function as parable. The manner in which the presence of light directs attention serves as an analogy for how the availability of certain techniques, tools, and models affect what gets known and what does not. For instance, with "economist" substituted for "man," the story becomes a timely warning about the self-induced blind spots of a profession. ${ }^{78}$ The joke has served as a warning of the disastrous consequences of how the ease of measuring certain effects (e.g., short-term indicators for tumor shrinkage) over others (long-term survival rates for patients) skews medicine. ${ }^{79}$ These are themes central to Absence in Science, Security and Policy. Both in terms of social life and social research, ignorance and absence can result from attention being directed here rather than there.

What I want to focus on in particular though is how this lesson about "blinders" relies on a visual metaphor. Depending on exactly how it is told, in this joke, light represents knowledge or at least the means to it. As such, while serving as a guard against the bounds of what is known, the Streetlight Effect joke does so through one way of sensing the world.

The association of the visual with knowledge (in preference to other senses) is arguably widespread in Western thought and scholarship. ${ }^{80}$ As some examples, the rise of reason over doctrine that began in seventeenth-century Europe is termed "Enlightenment." Words like "observe," "reflection," and "field" permeate the language of scholarship, as they have permeated this chapter. Striving for transparencyshining a light into dark corners-is a way of rendering something knowable because to enable something to be visible is to make it comprehendible. It can be counted, described, gotten the measure of, and so on. Seeing is even said to be believing. Contrarily, when one's view is obscured, when objects are hidden, or when one is kept in the dark then "insight" is diminished.

Seeing and sight, in turn, are aligned with certain manners of conceptualizing the objects being viewed. Objects become conceived in terms of surface and depth, size and volume, as well as interior and exterior. The task of viewing is one of exposing things to light or moving some from the background to the foreground. 
The reliance on a visual metaphor then is contingent and consequential. It favors particular ways of conceiving what is at stake.

At this point in the argument, one way to proceed would be to switch sense doors. Instead of sticking with sight, the argument could turn to examining how thinking with metaphors for touch, taste, hearing, and smell could offer by way of new sensitivities. This is not the course that will be followed. Instead, I want to keep with the dominant visual metaphor.

The basis for this continuing engagement is the recognition that sight is limited as an underlying metaphor because conventional ways of thinking about seeing only partly cover what takes place in seeing. Staying with this recognition is the basis for seeking new possibilities. ${ }^{81}$

In relation to the physical world, seeing is not simply about perceiving what there is. Given the vast distances of space, a look up in the night's sky will make visible many objects which no longer exist in an ordinary sense. ${ }^{82}$ Zoom in to the stars and other complications arise. Black spots are clearly visible on images of the Sun. These do not indicate the absence of light. Rather it is the contrast with the surroundings that makes these brilliantly radiant areas dark. Rainbows appear in the sky, but to take that appearance as indicating they possess substance akin to other visible objects would be a mistake. Alternatively, that which is not visible can still be perceptually present, as in looking at a tomato, a book, a piece of furniture, and so on. We can in some meaningful way sense the backs of such objects even if they are occluded from view. ${ }^{83}$ Additionally, we don't perceive everything that is visible because there is simply too much to take in with any viewing. This text is being seen by you as the reader, but not simply the whole book in its totality at once. ${ }^{84}$ Instead, focus is directed, and focus is partiality by definition. And finally, too much light can be blinding. ${ }^{85}$ As a result of the sort of points, the conflation of the visible, the present, and the known is problematic.

Acknowledging the potential and the limitations of knowing as seeing, I want to ask what kind of alternative metaphors for the work of seeing might be helpful in attending to the absence of concern. Is there a guiding metaphor or analogous example that might sharpen the sense of what is required to examine how implications of science and technology are and are not constituted?

This chapter advances a way of seeing relating to autostereograms. Autostereograms were popularized in the 1990s through books such as the Magic Eye series. These consist of two-dimensional repeating 


\section{Brian Rappert}

patterns that, when viewed in a certain manner, enable a three-dimensional image to become seen: a car, a flower, a complex geometrical shape. Often referred to as a trick of the eye, autostereograms rely on the difficulty of the brain in matching together the images of repeating patterns received by each eye. By matching certain parts of the image together that would not normally be matched, a three-dimensional image with depth appears.

As an object, that three-dimensional image has intriguing status in relation to the themes of this volume. It is both there and not. The image-for instance a flower with an intricate weaving of petals-is both there in the sense of having been intentionally inscribed by a stereogram artist as well as not there in the sense of not being immediately visible in the patterning. As many viewers of Magic Eye experience, this ambiguity fosters curiosity. Seeing a three-dimensional flower where there was before nothing of the sort lends itself to wonder about what is being seen and how this is so.

Also in terms of its object status, popularized accounts of autostereograms often tend to treat what is relieved as one fixed thing. ${ }^{86}$ Herein there is the surface-viewing available to all those with able sight and the hidden picture that can be discerned by those skilled in how to look. But viewing an autostereogram is not simply seeing a given uniform something. For instance, images can come (and go) in varying ways. Initially a single line or an edge of something might be perceived. This presents its own picture. Eventually, or maybe, the mind grasps hold and solidifies the movements of focus and haziness into a conventional image-like a flower-that can be named and this rendered familiar. However, in the process of viewing an autostereogram, recognition and labeling can be appreciated as an achievement (rather than an automatic capability). The work of seeing is detectable in the relatively slow formation of the images. What image does come into view depends on the viewer as well. Interestingly once an image solidifies, it is then possible to make minor bends and tilts in the viewing surface so as to modify what is being seen. As well, what is seen is not simply the object the stereogram artist hid inside the repeating pattern. The object perceived is constituted by the merger of the (typically colorful and vibrant) surface patterning and the hidden image. The two together impart a lucid quality to what is viewed that often means that an autostereogram looks more vivid and sharper than what is seen conventionally.

I am not primarily interested in the object status of an autostereogram in terms of its metaphorical potential though. Rather, I want to think about what the practice of construing the image signals for the relations 
to objects of study. Seeing an autostereogram might be a trick of the eye, but it is so in two meanings of the word "trick": a scheme that fosters an "illusion," but also a skilful feat of doing. It is not possible just to focus as one typically does (as in reading this text) to see a three-dimensional image. One will not appear by intently peering either. Neither would one appear by looking at the back pages of a Magic Eye book for the key of what is hidden and then trying to somehow find the image camouflaged within the repeating pattern. Instead, seeing requires disrupting habits. Methods of observation need to be learned and employed, methods that both enable new ways of viewing while they displace others. ${ }^{87}$

Common techniques include holding the autostereogram close, attempting to look through it, and then gradually moving it away. Another is to look through an object nearby and then to slowly place the autostereogram within your line of sight. A shared feature of many methods though is the need to cultivate a relaxed but at the same time attentive gaze. Attempts to intentionally focus on an emerging image will take it out of view. Tensing up is likewise counterproductive. Instead one needs to train receptiveness to the shifting movements within one's vision. That cannot be forced, but it does not come about by idle looking either. If the viewer is able to receptively stay with their unfolding experience in a manner that opens up to it, it is possibly to perceive new phenomenon.

Purposely cultivating ways of opening up (rather than grasping on) to the objects of study is a central theme of the chapters in Absence in Science, Security and Policy. For instance, in the other chapter of Part I, Brian Balmer offers other strategies for skilfully becoming aware. In "An Open Day for Secrets" Brian Balmer employs the notion of steganography from cryptography—how objects can be hidden in plain sight-to question ignorances and uncertainties associated with the (potentially malign) applications of science. Through investigating how concerns with the applications of science were handled within the history of the UK biological warfare program while also attending to the demands of such an investigation, his chapter will develop a contention made by Balmer elsewhere. Namely, that the process of assembling a historical narrative from declassified documents itself constructs transparency, resulting in a narrative made of fragments but which "reads as if it is an open window on past events." 88 His close examination of the first open day at Britain's main biological defense establishment, suggests how matters are kept secret by drawing attention to their very secrecy. As well as being told what they would see, visitors were told what they would not see. 
Other contributors to this volume are likewise acting in a manner analogous to the requirements of seeing autostereogram: disrupting habitual ways of looking, questioning what has been grasped and not, and attending to the qualities of the objects of study as shaped by our methods for attention. In Part II, "Practices of Inattention," a number of cases are detailed whereby implications of science and technology are rendered nonconcerns while the authors also consider what this means for inquiry. In "What ELSA Makes Small in Nanomedicine" Michael Schillmeier examines how the framing of the implications of engaging with nanomedicine through the lens of ELSA results in some gaining salience and others not. In response to the humanist understanding of politics, the social, and society implicit within ELSA frameworks he argues that a "more-than-human" approach is vital in understanding and assessing nano-scaled medical innovations. He outlines recent theorizing in STS to signal the many possibilities for such an approach.

Drawing on his long-time work experience in the UK Foreign and Commonwealth Office, John Walker's chapter ("Missing the ObviousCoping with Scientific and Technological Change in Chemical and Biological Weapons Arms Control") considers how the international treaties prohibiting biological and chemical weapons have tried to anticipate the implication of scientific and technological change for treaty provisions. That has meant trying to grasp what is seemingly hard to understand, unknown, unintelligible, collectively disowned, nonobvious, or simply beyond expression. It also constitutes absence as temporally bound, as he asks how the original negotiators of the treaty dealt with future developments that could only be foreseen in very vague ways such as science changes, geo-politics changes.

Felicity Mellor's "Non-news Values in Science Journalism" asks how certain implications of science never figure within news coverage. She does so by questioning conventional ways of thinking within media studies and practicing science journalism. More specifically, Mellor argues how "non-news values" particular to science structure what is included and omitted from science reporting. These nonnews values derive from highly idealist views of science, which themselves construe questions of interests and fallibility as nonissues.

In "Project Jefferson: Technological Surprises and Critical Omissions," Kathleen Vogel questions how the US Department of Defense multimillion-dollar-funded "Project Jefferson" tried to assess emerging bioweapons threats. Vogel details not only what it was designed to do, but also what important omissions resulted from its design and implementation. She argues that the Project's focus on technical aspects of 
bioweapons threats drew intelligence attention from a broader array of ways to conceptualize the nature of threats-for instance by attending to more complex sociotechnical dimensions of capabilities. The chapter contends that analytic regimes such as Project Jefferson, with its technical objects and social machinery, can powerfully structure the way officials think, resulting in analytic and policy blind spots.

In the last chapter of Part II, Sam Weiss Evans and Emma Frow examine the shaping of concerns and nonconcerns relating to biosafety and biosecurity in two high-profile synthetic biology initiatives: the US-based Synthetic Biology Engineering Research Center (Synberc), and the international genetically engineered machine (iGEM) student competition. They identify a variety of examples and strategies by which actors within these initiatives are rendering safety and security concerns visible and invisible. The suggestion is that each reflects a particular, situated understanding of and approach to "taking care," with different implications for how the institutions, epistemic structures, practitioner identities, and artifacts of synthetic biology may develop. In these examples, they also strive to account for their own involvement as social scientists in the activities of Synberc and iGEM.

To return to the autostereogram metaphor, the chapters of Part III "Sights and Sensitivities" ask about the fruits of what comes into view when we attend to receptiveness. In "What Counts as the Hostile Use of Chemicals?" James Revill and Brett Edwards examine how only certain forms of violence have been regarded as instances of "chemical and biological weapon" attacks. Notably, despite their reliance on the toxicity of chemicals (and thus technically being chemical weapons under existing international treaties), the large number of acid attacks, disproportionally affecting women, that are perpetrated each year are not labeled as chemical weapon attacks. The contingency of how categories are constructed within the international community provides a basis for Revill and Edwards to offer a distinctive take on existing diplomatic efforts to control weapons of mass destruction.

As with many other contributions to this volume, Gerald Walther and Malcolm Dando's chapter "A Phoenix of the Modern World" juxtaposes relatively identified and not identified implications of science. They use the mythological phoenix as a metaphor to explore the reemergence of the National Science Advisory Board. Although the rebirth and rise of the phoenix from the ashes is often drawn on metaphorically, Walther and Dando also draw attention to the period of absence and change while the phoenix is dormant. Furthermore, they ask what the mixed and uneven regard for the potential social consequences of brain 
research means for practical efforts to avert such possibilities from being realized.

Regard for the implications of how concern is constituted and what this means for action is also a theme of "On Forming What isn't There." In this chapter Richard Moyes draws on his long time experience as a campaigner about the humanitarian effects of armed conflict to reflect on how contentions associated with the effects of weapon systems have been framed, as well as what these have meant for efforts to reduce injury and death to civilians. He offers practical experiences about how the adoption of particular ways of focusing can open up new space, opportunities that can be built on to bring about major reform of international conduct. Finally, his chapter examines the limitations about what can be said about such processes due to the constraints of diplomatic professional discourses.

Bounded professional discourse though characterizes all the contributions to Absence in Science, Security and Policy. In recognition of this, we invite the reader to attend to the chapters of this volume through considering what they state and what they do not, how their arguments are understood and how they are not, as well as what sort of skills for opening up to new possibilities can be cultivated.

\section{Notes}

1. My thanks to the participants of the September 27-28, 2013 conference "Issues and Non-issues in Science and Medicine" and the Biological Interest Group seminar on October 27, 2014, both at the University of Exeter, for their comments on earlier versions of this chapter. Special thanks as well to Brian Balmer, Giovanna Colombetti, Michael Schillmeier, Guillem Palà, John Dupre, Sabina Leonelli, Nadine Levin, Catelijne Coopmans, Morgan Meyer, and Gonzalo Correa. Research Councils UK grant ES/K011308/1 "The Formulation and Non-formulation of Security Concerns" provided me with time to prepare this chapter.

2. See, for instance, Francis, L.P., Battin, M.P., Jacobson, J.A., Smith, C.B., and Botkin, J. 2005. "How infectious diseases got left out-And what this omission might have meant for bioethics," Bioethics 19(4): 307-322.

3. Cooper, R. and Law, J. 1995. "Organization: Distal and proximal views," in S.B. Bacharach, P. Gagliardi, and B. Mundell (eds). Research in the Sociology of Organizations: Studies of Organizations in the European Tradition. Greenwich, CT: JAI Press.

4. Although there have been those that have crossed over this divide, for instance, Wright, S. (ed.). 2001. Biological Warfare and Disarmament. London: Rowman \& Littlefield; and Green, S. 2005. "E3LSI research: An essential element of biodefense," Biosecurity and Bioterrorism 3(2): 128-137.

5. Lock, Margaret. 2001. Twice Dead. London: University of California Press.

6. Kosko, Bart. 1993. Fuzzy Thinking. London: Flamingo. 
7. Close, Frank. 2009. Emptiness. Oxford: Oxford University Press: 26.

8. Schillmeier, M. 2009. "Actor-networks of dementia," in Ders and J. Latimer (ed.) Un/knowing Bodies. Oxford: Blackwell: 149.

9. See Pluot, S. 2009. "Include me out," in John Armieder, Matthieu Copeland, Laurant Le Bon, Gustav Metzger, Mai-Thu Perret, Clive Phillpot, and Philippe Pirotte (eds) Voids: A Retrospective. Zurich: JPR | Ringier: 264-276.

10. Paglen, T. 2010. "Goatsucker: Toward a spatial theory of state secrecy," Environment and Planning D 28: 759-771 and Komaromy, Carol. 2010. "Dying spaces and dying places," in Jenny Hockey, Carol Komaromy, and Kate Woodthorpe (eds) The Matter of Death: Space, Place and Materiality. Houndmills: Palgrave.

11. Sontag, S. 1977. On Photography. London: Penguin Books: 15. See also Barthes, R. 1982. Camera Lucida. London: Jonathan Cape.

12. Noë, Alva. 2012. Varieties of Presence. Cambridge, MA: Harvard University Press: Chapter 5. In a similar vein, entering an abandoned house can evoke a sense who was there before.

13. Leader, Darian. 2002. Stealing the Mona Lisa. New York: Counterpoint.

14. Franke, W. 2007. On What cannot be Said Volume 1. Notre Dame: University of Notre Dame Press.

15. For instance, see Law, John. 2002. "On hidden heterogeneities: Complexity, formalism and advanced aircraft design," in John Law and Annemarie Mol (eds). Complexities. London: Duke University Press: 116-141.

16. See Hetherington, Kevin. 2004. "Secondhandedness: Consumption, disposal, and absent presence," Environment and Planning D: Society and Space 22: 157-173.

17. For an examination of the ascetics of redaction, see Office of Experiments. 2013. "On being overt secrecy and covert culture," in Elizabeth Fisher and Rebecca Fortnum (eds). On Not Knowing. London: Kettle's Yard.

18. Phillips, I. 2012. "Hearing and hallucinating silence," in F. Macpherson and D. Platchias (eds). Hallucination. Boston: MIT Press.

19. Wooffitt, Robin and Holt, Nicola. 2011. Looking In and Speaking Out. Exeter: Imprint Academic: 65-67.

20. On lived experience and absence, see Frers, Lars. 2013. "The matter of absence," Cultural Geographies 20(4) doi: 10.1177/1474474013477775.

21. See Rappert, B. 2012. How to Look Good in a War. London: Pluto: Chapter 1.

22. Coopmans, Catelijne. 2013. "Visual analytics as artful revelation," in C. Coopmans, J. Vertesi, M.E. Lynch, and S. Woolgar (eds). Representation in Scientific Practice Revisited. Cambridge, MA: MIT Press.

23. Meyer, M. 2012. "Placing and tracing absence," Journal of Material Culture 17(1): 103-110.

24. Wooffitt and Holt. 2011. Looking In and Speaking Out.

25. Tao Te Ching: Chapter 11.

26. Kasulis, T. P. 1981. Zen Action/Zen Person. Honolulu, HA: University of Hawaii Press and Walsh, T. 1998. The Dark Matter of Words. Carbondale, IL: Southern Illinois University Press.

27. Ginzburg, C. 1980. The Cheese and the Worms. Baltimore, MD: Johns Hopkins University Press: 128.

28. Despite notable exceptions, including Bille, Mikkel, Frida Hastrup, and Tim Flohr Sorensen, (eds). 2012. An Anthropology of Absence: Materializations of 
Transcendence and Loss. New York: Springer and Law, John. 2002. “On hidden heterogeneities": 116-141.

29. Frickel, S. 2014. "Absences," Social Epistemology 28(1): 86-95.

30. Francis, Battin, Jacobson, Smith, and Botkin. 2005. "How infectious diseases got left out." As well, note that such an identification of "knowledge gaps" is a routine justification for advancing new fields of research. In the manner much of social and ethical research justifies itself as attending to what has not been (adequately) attended to before, a sense of absence functions as both an organizing raison d'etre for further research as well as (more or less direct) critique of past research. Pitched in this manner at least, what is (relatively) absent is a significant (if not the primary) topic of study in the social sciences.

31. Suryanarayanan, Sainath, and Daniel Lee Kleinman. 2013. "Be(e)coming experts: The controversy over insecticides in the honey bee colony collapse disorder," Social Studies of Science 43(2): 215-240.

32. Wæver, O. 1995. "Securitization and desecuritization," in D. L. Ronnie (ed). On Security. New York: Columbia University Press.

33. Just as new topics come into the fore over time, others recede in the background. Today, some have argued that the relation between genetics, race, and intelligence has become a kind of "forbidden knowledge" among (American) sociologists due to its political potency; see Kempner, J., Merz, J.F., and Bosk, C.L. 2011. "Forbidden knowledge: Public controversy and the production of nonknowledge," Sociological Forum 26(3): 475-500.

34. Brekhus, Wayne. 1998. "A sociology of the unmarked: Redirecting our focus," Sociological Theory 16: 34-51.

35. Proctor, R. 2008. "Agnotology: A missing term," in R. Proctor and L. Schiebinger (eds). Agnotology. Stanford, CA: Stanford University Press.

36. Ibid.: 1-2.

37. For an example of one attempt to set out an epistemology of ignorance, see Mills, Charles. 1997. The Racial Contract. Ithaca: Cornell University Press. For explicit analysis of ignorance with regard to science, see the Special Issue of Science Communication Volume 15 Number 2.

38. Croissant, J. 2014. "Agnotology: Ignorance and absence, or towards a sociology of things that aren't there," Social Epistemology 28(1): 4-25.

39. For example, Dilley, R. 2010. "Reflections on knowledge practices and the problem of ignorance," Journal of the Royal Anthropological Institute 16: S176-S192 and Chua, L. 2009. "To know or not to know? Practices of knowledge and ignorance among Bidayuhs in an 'impurely' Christian world," Journal of the Royal Anthropological Institute 15: 332-348. Although in contrast see Mair, Jonathan, Kelly, Ann, and Casey High. 2012. "Making ignorance an ethnographic object," in Casey High, A. Kelly, and J. Mair (eds). The Anthropology of Ignorance. New York: Palgrave: 1-32.

40. As well, attempts to counter a perceived absence of social analysis of ignorance through greater social research analysis can hazard the very production of ignorance by academics if the actions of social actors are attributed with too much coherence and intentionality. See Rappert, B. 2012. "States of ignorance: The unmaking and remaking of death tolls," Economy and Society 41(1): 42-63. 
41. Some of the language about absences in social research hazards forwarding nonentities as objects for study, as in Fowles's suggestion that "Absences push back and resist. They prompt us into action. And like present things, absences also have their distinctive affordances and material consequences." Fowles, S. 2010. "People without things," in M. Bille et al. (eds) An Anthropology of Absence: Materializations of Transcendence and Loss. Berlin: Springer: 24, quoted from Meyer. 2012. "Placing and tracing absence".

42. Rappert, B. 2013. "Present absences: Hauntings and whirlwinds in -graphy," Social Epistemology 28(1): 41-55.

43. For instance, see Lebow, R.N. (2010) Forbidden Fruit: Counterfactuals and International Relations. Princeton, NJ: Princeton University Press; and Dimitrov, R., Sprinz, D., DiGusto, G., and A. Kelle (2007) "International nonregimes: A research agenda" International Studies Review 9: 230-258.

44. Mazzei, L.A. 2003. "Inhabited silences: In pursuit of a muffled subtext," Qualitative Inquiry 9: 355-368.

45. See, for example, Fricker, M. 2007. Epistemic Injustice: Power and the Ethics of Knowing. Oxford: Oxford University Press; Ginzburg. 1980. The Cheese and the Worms; Mazzei. "Inhabited silences" and Franke. 2007. On What Cannot be Said.

46. For a discussion of this in relation to ignorance, see Mair, Kelly, and High. 2012. "Making ignorance an ethnographic object".

47. See, for instance, Gusfield, J. 1981. The Culture of Public Problems: DrinkingDriving and the Symbolic Order. Chicago, IL: University of Chicago Press; Dimitrov, Sprinz, DiGusto, and Kelle. 2007. "International nonregimes"; and Eliasoph, N. 1998. Avoiding Politics. Cambridge, MA: Cambridge University Press.

48. Cunningham-Burely, S. and Kerr, A. 1999. "Defining the 'social'," Sociology of Health \& Illness 21(5): 647-668.

49. Frith, L., Jacoby, A., and Gabbay, M. 2011. "Ethical boundary-work in the infertility clinic," Sociology of Health \& Illness: 1-16.

50. Brekhus. 1998. "A sociology of the unmarked" and Dimitrov, Sprinz, DiGusto, and Kelle. 2007. "International nonregimes"

51. As argued by Bacchi, C. L. 1999. Women, Policy and Politics. London: Sage

52. Indeed, researchers' notions of the moral structure of their work might well be at odds with their day-to-day activities. See Kempner, Merz, and Bosk. 2011. "Forbidden knowledge," op. cit. note 30.

53. Ibid.

54. Rayner, S. 2012. "Uncomfortable knowledge," Economy and Society 41(1): 107-125.

55. Benford, R.D. and Snow, D.A. 2000. "Framing processes and social movements," Annual Review of Sociology 26: 11-39 and Gamson, W. and Modigliania, A. 1989. "Media discourse and public opinion on nuclear power," American Journal of Sociology 95(1): 1-37.

56. For a further discussion of related points see Woolgar, S. and Pawluch, D. 1985. "Onotological gerrymandering," Social Problems 32(3): 214-227.

57. Chambliss, D. 1996. Beyond Caring: Hospitals, Nurses and the Social Organization of Ethics. London: University of Chicago Press. See as well Morris, N. and Balmer, B. 2006. "Volunteer human subjects' understandings of their 
participation in a biomedical research experiment," Social Science \& Medicine 62(4): 998-1008.

58. Bacrach, Peter and Morton Baratz. 1962. "Two faces of power," American Political Science Review 57: 632-642.

59. Likewise, studies of social framing, the exercise of domination, or the reproduction of hegemony ask why some cares never get on the policy agenda or others simply never get recognized at all. See, for instance, Eliasoph. 1998. Avoiding Politics.

60. Lukes, Steven. 1974. Power: A Radical View. London: Macmillan.

61. See Balmer, Brian (2012) Secrecy and Science: A Historical Sociology of Biological and Chemical Warfare. Farnham: Ashgate on scientific advisors as "socially legitimated doubters."

62. See the 2006 special issue of Political Studies Review, volume 4 for a lengthy consideration of these and related points.

63. Dimitrov, R. 2006. Science and International Environmental Policy. London: Rowman and Littlefield.

64. For a discussion of such issues, see Social Problems 39(1): 35-39 and Gordon, A. 1993 "Twenty-two theses on social constructionism," in J. Holstein and G. Miller (eds). Reconsidering Social Constructionism. New York: Aldine de Gruyter.

65. Woolgar and Pawluch. 1985. "Onotological gerrymandering".

66. Latour, Bruno. 2004. "Why has critique run out of steam? From matters of facts to matters of concern," Critical Inquiry 30 (Winter): 225-248.

67. Lynch, Michael. 2013. "Ontography: Investigating the production of things, deflating ontology," Social Studies of Science 43(3): 444-462.

68. As in Rappert. 2012. "States of ignorance".

69. See also Lynch. 2013. "Ontography".

70. Puig de la Bellacasa, Maria 2011. "Matters of care in technoscience: Assembling neglected things," Social Studies of Science 41(1): 85-106.

71. On this point see Silverman, C. 2012. Understanding Autism. Oxford: Princeton University Press.

72. Ibid: $94-95$.

73. Bacchi. 1999. Women, Policy and Politics.

74. Law, J. and Marianne Lien. 2012. "Slippery: Field notes in empirical ontology," Social Studies of Science 43(3): 363-378: 364.

75. Ibid.

76. See as well Vertesi, J. 2014. "Drawing as," in C. Coopmans, J. Vertesi, M.E. Lynch, and S. Woolgar (eds). Representation in Scientific Practice Revisited. Cambridge, MA: MIT Press.

77. As examples of alternative ontological politics, see Papadopoulos, D. 2014. "The politics of matter," Social Epistemology 28(1): 70-85 and Puig de la Bellacasa, Maria. 2014. "Encountering bioinfrastructure: Ecological struggles and the sciences of soil," Social Epistemology 28(1): 26-40.

78. The notion that classical neoliberal economics cultivates habits of thinking that systematically miss out on major facets of the economy-such as private debt and money-is one that has been made with renewed vigor since 2008 financial crises. See Keen, S. 2011. Debunking Economics: The Naked Emperor Dethroned? London: Zed. For another account of institutionalized blindness, see Das, Satyajit. 2006. Traders, Guns \& Money. Harlow: Pearson Education Limited. 
79. Freedman, David H. 2010. "Why scientific studies are so often wrong: The streetlight effect," Discover July-August. Available at: http://discovermagazine. com/2010/jul-aug/29-why-scientific-studies-often-wrong-streetlight-effect.

80. See Bull, M. 1999. Seeing Things Hidden. London: Verso and Howes, D. 1991. "Introduction," in D. Howes (ed.). The Varieties of Sensory Experience: A Sourcebook in the Anthropology of the Senses. Toronto: University of Toronto Press: $3-21$.

81. For instance, as pursued by Haraway in her efforts to reclaim the vision as an embodied type of knowing rather than a type of knowing that sees everything from nowhere. Haraway, Donna. 1988. "Situated knowledges: The science question in feminism and the privilege of partial," Feminist Studies 14(3): 575-599.

82. See Walsh. 1998. The Dark Matter of Words: 3-4.

83. As taken up by Noë, Alva. 2012. Varieties of Presence.

84. On these last two points, perceptual presences are discussed in-depth in Noë, Alva. 2012. Varieties of Presence.

85. A metaphor for information pursued in Tsoukas, Haridimos. 1997. "The tyranny of light," Futures 29(9): 827-843.

86. For an analysis of object metaphors for absence and presence, see Law, John, and Annemarie Mol. 2001. "Situating technoscience: an inquiry into spatiality's," Environment and Planning D 19: 609-621.

87. And, different methods work for different people and for some none may work-which is another aspect of exclusion.

88. Balmer. 2012. Secrecy and Science: 15.

Except where otherwise noted, this work is licensed under a Creative Commons Attribution 3.0 Unported License. To view a copy of this license, visit http://creativecommons.org/licenses/by/3.0/ 